\title{
Limbic lesions and consummatory behavior in the rat
}

\author{
MICHAEL L. THOMKA, LAWRENCE R. MURPHY, and THOMAS S. BROWN \\ DePaul University, Chicago, Illinois 60614
}

\begin{abstract}
The consummatory behavior of normal rats and rats with lesions of the hippocampus, neocortex, entorhinal cortex or transections of the fornix was compared during 3 days of ad-lib feeding. The results showed that none of the groups differed on the mean amount of food or water consumed. However, the rats with lesions of the hippocampus dropped a significantly larger portion of their food ration through the wire mesh floors of the cages. The results are discussed in terms of a possible confounding which could occur when rats with hippocampal lesions are maintained on fixed rations of food and housed in wire mesh cages.
\end{abstract}

Several lesions of the limbic system have been shown to alter the eating and drinking patterns observed in the normal rat. Dickinson (1973) found that rats with septal lesions adopted a prandial mode of drinking, alternating short bouts of eating and drinking during the feeding period. Murphy, Race, and Brown (1975) reported a similar effect in male rats with hippocampal lesions but not in female rats with comparable ablations.

It has been a repeated observation in our laboratory that the eating pattern of male rats with hippocampal lesions is dramatically altered (female rats with hippocampal lesions have not been observed). When fed in suspended wire mesh cages (perhaps the predominant mode of housing for rats in laboratories throughout the country), rats with hippocampal lesions consistently waste amounts of food far in excess of what is seen for the normal animal. The waste consists of the animal dropping pieces of lab chow pellets which, when small enough, fall through the floor of the suspended cage. Casual observation of this was also mentioned by Boitano, Lubar, Auer, and Furnald (1968). The present study was undertaken to quantify the amount of food dropped by rats with hippocampal lesions. Moreover, the present experiment also sought to determine the involvement of the fornix and the entorhinal cortex in this unusual eating pattern.

\section{METHOD}

\section{Subjects}

30 male Sprague-Dawley rats, weighing approximately $355 \mathrm{~g}$ at the time of testing, were used. The animals were individually housed in cages of .5-in. wire mesh. The cages were 7 in. wide, $7 \mathrm{in}$. high, and $9.5 \mathrm{in}$. long and suspended so that the floor of the cage was 3 in. above the dropping pan. Food and water were always available. The animals were randomly assigned to one of five groups $(\mathrm{N}=6$ per group). Four were surgical treatment groups, whereas the fifth one was the normal control group. The surgical preparations consisted of lesions of the hippocampus, neocortex, entorhinal cortex, and transections of the fornix.

\section{Surgery}

Surgery was performed under sodium pentobarbital anesthesia

This research was supported in part by the State of Illinois Mental Health Fund Grant 490-13-RD to Dr. Thomas S. Brown.
$(40 \mathrm{mg} / \mathrm{kg})$ which was supplemented with $.1 \mathrm{cc}$ of atropine $(.4 \mathrm{mg} / \mathrm{ml})$. For the rats receiving the hippocampal lesions, the cortex overlying the hippocampus was first removed. The hippocampus itself was then aspirated under visual guidance as completely as possible. The neocortical group received cortical lesions comparable in size and location to the cortex ablated in the hippocampal lesion. The lesions in the entorhinal and fornix groups were performed with a temperature-controlled radio-frequency lesion maker (Radionics Model RFG-4). The stereotaxic coordinates for the fornix transections were A-P 0.0 (at bregma), L 1.0, and $\mathrm{H} 4.0$ from the surface of the brain, according to the Pellegrino and Cushman (1967) atlas. In the fornix lesion, the electrode tip temperature was raised to $55^{\circ} \mathrm{C}$ and held there for $1 \mathrm{~min}$. Two placements on each side were made for the entorhinal lesions. The coordinates were as follows: $\mathrm{A}-3.0$, L 6.5, and $\mathrm{H} \mathrm{9.5;} \mathrm{A}-5.0, \mathrm{~L} 6.5$, and $\mathrm{H} \mathrm{8.5}$. The electrode tip temperature was raised to $60^{\circ} \mathrm{C}$ and held there for $1 \mathrm{~min}$ for each of the four penetrations. Subjects in the normal control group were placed in the stereotaxic apparatus, the scalp was incised, and the temporal muscles retracted. The skull, however, was not opened.

\section{Procedure}

The animals were allowed 3 weeks to recover from surgery before observations were taken. For each of 3 days following the postoperative recovery period, each animal received $40 \mathrm{~g}$ of Rockland mouse/rat food pellets and $100 \mathrm{ml}$ of water. These amounts allowed for ad-lib feeding and drinking. Paper was placed under each cage to collect any food which was dropped through the floor of the cage. The amount of food accumulated under each cage was weighed each day on a scale accurate to $.01 \mathrm{~g}$. Water and food intake were also recorded for each day. Daily food intake was obtained by subtracting the amount of food left in the cage plus the amount dropped from the $40 \mathrm{~g}$ ration.

\section{Histology}

When behavioral testing was completed, the animals were sacrificed by an overdose of Nembutal, perfused with saline and Formalin, and the brains were removed. The brains were embedded in paraffin, and sections were stained according to the method of Klüver and Barrera (1953). Because of an unfortunate accident, all brains of the fornix group were lost for histology. Their data are reported, but final interpretation of that data will obviously have to wait for a replication of the present findings.

\section{RESULTS}

\section{Histological}

Histological analysis revealed that the lesions were 
Table 1

Mean Measurements Over 3 Days

\begin{tabular}{lccc}
\hline Lesion Group & $\begin{array}{c}\text { Food } \\
\text { Eaten } \\
(\mathrm{g})\end{array}$ & $\begin{array}{c}\text { Water } \\
\text { Intake } \\
(\mathrm{ml})\end{array}$ & $\begin{array}{c}\text { Food } \\
\text { Dropped } \\
(\mathrm{g})\end{array}$ \\
\hline Hippocampus & 18.90 & 43.92 & $14.65^{*}$ \\
Neocortex & 19.77 & 40.48 & 7.74 \\
Entorhinal Cortex & 18.21 & 39.36 & 6.87 \\
Fornix & 18.03 & 43.30 & 7.24 \\
Normal & 19.20 & 42.77 & 5.32 \\
\hline
\end{tabular}

${ }^{*} p<.01$

generally as intended in those brains that were available for histology. The lesions of the neocortex and hippocampus were virtually identical to those already published in other reports from this laboratory (Murphy \& Brown, 1970; Murphy \& Brown, 1974; Thomka \& Brown, 1975). The lesions in the entorhinal group were generally well placed, but some discrepancies from the intended lesions did occur. Destruction of tissue at the anterior placement $(\mathrm{A}-3.0)$ was higher than intended, i.e., the dorsal border of the lesion extended beyond the rhinal fissure. This was not the case with the posterior placement. The medial extent of these lesions invaded the lateral surface of the posteroventral hippocampus. This occurred in varying degrees in all animals in this group. This invasion of the hippocampus was not sufficient, however, to affect the performance of the animals on the measures obtained in the present paper. The brains of the animals in the fornix group were lost for histological analysis.

\section{Behavioral}

The behavioral results of the present experiment are shown in Table 1. As regards the mean amount of water drunk over the 3 days of observation, a one-way analysis of variance computed for the amount of water consumed revealed no significant differences among any of the surgical groups $(\mathrm{p}>.05)$.

Table 1 also shows the mean amount of food eaten and food dropped by each group. Because the amount of food eaten and the amount of food dropped (for individual animals) were not independent measures, a two-way multivariate analysis of variance was used with food eaten and food dropped as dependent variables. A significant lesion effect was obtained across measures $(\mathrm{p}<.01)$. The days and interaction effects, however, did not reach significance $(\mathrm{p}>.05)$.

Comparisons between group means indicated that rats with hippocampal lesions dropped significantly more food ( $p<.01)$ than any of the other groups. All other comparisons between groups for the amount of food dropped did not reach significance $(p>.05)$. Comparisons of group means for the amount of food eaten did not result in any significant difference among the five groups $(\mathrm{p}>.05)$.

\section{DISCUSSION}

The findings of the present study replicate earlier data which show that hippocampal lesions do not increase daily water intake or food consumption (Boitano et al., 1968, Kim, Choi, Kim, Chang, Park, \& Kang, 1970; Murphy \& Brown, 1970). The present results also serve to quantify and verify the casual observations of several researchers (Boitano et al., 1968; Morey, Note 1.), who noted that rats with hippocampal lesions drop large amounts of their food ration. In the present study, normal animals dropped approximately $13 \%$ of their daily food ration in contrast to animals with hippocampal lesions that dropped $37 \%$ of their food.

It is not clear at this time why only the large hippocampal lesions resulted in increased food spillage. It was anticipated that disruption of the connections of the hippocampus which occur by way of either the fornix or entorhinal cortex would result in food spillage similar to that observed in the animals with hippocampal lesions. Though nothing definite can be stated with regard to the fornix fiber system, it does appear that lesions of the entorhinal cortex do not affect eating patterns as observed in the present experiment. It may be that both fiber systems must be interrupted before an effect is seen. Thus, only the animals with large hippocampal lesions would be expected to show the effect.

The results of the present study also have a practical application in the control of body weight and/or drive level in rats with hippocampal lesions. One could have a possible confounding effect if animals are maintained on a small fixed ration of food/day and the animals are housed in the popular suspended cages. Though animals are given the same amount of food, rats with hippocampal lesions would functionally receive less food due to the significant amount of food that is dropped through the cage floor.

\section{REFERENCE NOTE}

1. Morey, T. M. Hippocampal lesions and positive incentive motivation. Unpublished PhD dissertation, DePaul University, Chicago, Illinois, 1973.

\section{REFERENCES}

Boitano, J. J., Lubar, J. F., Auer, J., \& Furnald, M. Effects of hippocampectomy on consummatory behavior and movement inhibition in rats. Phy siology and Behavior, 1968, 3, 901-906.

Dickinson, A. Prandial drinking in rats with septal lesions. Physiology and Behavior, 1973, 10, 305-315.

Kim, C., Choi, H., Kim, J. K., Chang, H. K., Park, R. S., \& Kang, I. Y. General behavioral activity and its component patterns in hippocampectomized rats. Brain Research, 1970, 19, 379-394.

Klüver, H., \& Barrera, E. A. A method for the combined staining of cells and fibers in the nervous system. Journal of Neuropathology and Experimental Neurology, 1953, 12, 400-403.

Murphy, H. M., \& Brown, T. S. Effects of hippocampal lesions on simple and preferential consummatory behavior in the rat. Journal of Comparative Physiological Psychology, 1970, 72, 404-415.

Murphy, L. R., \& Brown, T. S. Hippocampal lesions and learned taste aversion. Phy siological Psy chology, 1974, 2, 60-64.

Murphy, L. R., Race, K. E., \& Brown, T. S. Behaviors emitted by rats with limbic lesions during feeding. Behavioral Biology, 1975 , in press.

Pellegrino, L. J., \& Cushman, A. J. A stereotaxic atlas of the rat brain. New York: Appleton-Century-Crofts, 1967.

Thomka, M. L., \& Brown, T. S. The effect of hippocampal lesions on the development and extinction of a learned taste aversion for a novel food. Physiological Psychology, 1975, in press. 